\title{
Aplikasi Pembelajaran IPA Untuk Siswa Homeschooling Pena
}

\author{
Nia Saurina \\ Prodi Teknik Informatika, Fakultas Teknik, \\ Universitas Wijaya Kusuma Surabaya \\ Email:niasaurina@gmail.com
}

\begin{abstract}
There are some straight rules for student, high discipline and formal learning without realizing could overload and made student not creative. Study at home or homeschooling could support maturity of the thinking and attitudes of students. Because mostly development of student could be monitored and communicated to their parents. Homeschooling X in Ketintang street, Surabaya offer homeschooling and have course which adapted with student's competence. One of the course is science or Ilmu Pengetahuan Alam (IPA). Science learn natural phenomena about life and physical world include human, animal, creature. This research is made science's application for student of Homeschooling $X$ so that tutor tutor could gave interesting and interactive course. Research testing in this research using Black Box method. The result that science's application could add student, course, exercise include mupltiple choices and classification. This application could gave correct answer when student can made true classification based on exercise. Beside that this application has average validation from matter expert in the amount of $84,76 \%$ with very good categories, and has average validation from media expert in the amount of 73,45\% with good categories, and has average validation from students in the amount of $87,17 \%$ with very good categories. Keywords: science teaching, homeschooling, android.
\end{abstract}

\begin{abstract}
Abstrak. Berlakunya seperangkat aturan yang sangat mengikat bagi peserta didik, penerapan disiplin yang terlalu kaku, dan suasana belajar yang terlalu formal tanpa disadari sering membebani dan memasung kreativitas peserta didik. Belajar di rumah atau homeschooling akan mendukung terhadap proses kematangan jiwa dan sikap anak. Karena hampir seluruh perkembangan kejiwaan anak bisa terpantau karena lebih gampang memantau dan mengkomunikasikan dengan pihak orang tua. Homeschooling Pena yang berada di jalan Ketintang, Surabaya menawarkan pembelajaran Homeschooling dengan materi yang disesuaikan dengan kompetensi siswa yang dimilikinya. Salah satu materi yang ditawarkan di dalam program tersebut adalah materi Ilmu Pengetahuan Alam (IPA). IPA atau sains merupakan ilmu yang mempelajari gejalagejala alam yang meliputi mahluk hidup dan mahluk tak hidup atau sains tentang kehidupan dan sains tentang dunia fisik. Penelitian ini bertujuan untuk menghasilkan aplikasi pembelajaran IPA yang ditujukan untuk siswa Homeschooling Pena agar dapat membantu para tutor atau pemberi materi memberikan materi pembelajaran yang menarik dan interaktif. Hasil pengujian penelitian ini menggunakan Black Box. Aplikasi Pembelajaran IPA untuk Siswa Homeschooling Pena dapat melakukan penambahan peserta didik, materi, soal latihan berupa pilihan ganda dan berupa klasifikasi. Aplikasi Pembelajaran IPA dapat menampilkan nilai siswa sesuai dengan jumlah jawaban yang benar. Selain itu aplikasi juga dapat memberikan jawaban BENAR saat siswa berhasil mengelompokkan mahluk hidup sesuai dengan soal latihan yang diberikan, sebaliknya aplikasi dapat memberikan jawaban SALAH saat siswa melakukan kesalahan dalam mengelompokkan mahluk hidup sesuai dengan soal latihan yang diberikan. Aplikasi
\end{abstract}


Pembelajaran IPA memiliki rata-rata validasi ahli materi sebesar 84,76\% dengan kategori sangat baik, rata-rata validasi ahli media sebesar 73,45 \% dengan kategori Baik, dan rata-rata validasi pengguna sebesar $87,17 \%$ dengan kategori sangat baik.

Kata kunci: pembelajaran IPA, homeschoolling, android.

\section{Pendahuluan}

Berlakunya seperangkat aturan yang sangat mengikat bagi peserta didik, penerapan disiplin yang terlalu kaku, dan Susana belajar yang terlalu formal tanpa disadari sering membebani dan memasung kreativitas peserta didik. Selain itu adanya persaingan antar peserta didik menyebabkan sebagian peserta didika merasa stress sehingga anak lebih memanding belajar sebagai kewajiban dan beban, bukan sebagai kebutuhan. Di era sekarang, mulai bermunculan lembaga-lembaga pendidikan alternative sebagai upaya mengatasi persoalan tersebut, salah satunya adalah Homeschooling (Sumardiono, 2007).

Di dalam jurnal internasional oleh Michelle Wichers (Wicher, 2006) yang berjudul "Homeschooling: Adventitious or detrimental for proficiency in higher education" menyimpulkan bahwa : Therefore the hypothesis was supported by a variety of researchers that homeschooled students performed as well or better academically as compared to traditional schooled individuals (Siswa yang belajar di rumah (homeschooling) lebih baik secara akademis dibandingkan dengan individu yang disekolahkan secara tradisional (disekolah)).

Belajar di rumah atau homeschooling akan mendukung terhadap proses kematangan jiwa dan sikap anak. Karena hampir seluruh perkembangan kejiwaan anak bisa terpantau karena lebih gampang memantau dan mengkomunikasikan dengan pihak orang tua. Jadi hambatan belajar mereka, baik secara fisik dan psikis, relatif lebih cepat diketahui dan dipecahkan. Proses kematangan jiwa ini sangat membantu kepercayaan diri untuk selalu belajar (Saputra, 2007).

Homeschooling di Indonesia mulai marak terjadi pada tahun 2005. Kehadirannya lebih dilatarbelakangi sebagai upaya mengantisipasi keberadaan sekolah regular (pendidikan formal) yang tidak merata ditiap-tiap daerah. Selain itu ada pula motivasi untuk memperkaya bentuk dan ragam pelaksanaan pendidikan khususnya anak berbakat / memiliki potensi khusus. Seiring merebaknya homeschooling di Indonesia semakin antusias pula minat orang tua menyekolahkan anaknya di homeschooling. Bahkan saat ini homeschooling telah menjadi tren di kota-kota besar di Indonesia. Dari fenomena tersebut dapat diperkirakan bahwa homeschooling semakin dibutuhkan masyarakat. Setidak-tidaknya keberadaan homeschooling akan memenuhi sekitar 10\% dari total jumlah anak di Indonesia (Kurniasih, 2009).

Homeschooling Pena yang berada di jalan Ketintang, Surabaya menawarkan pembelajaran Homeschooling dengan materi yang disesuaikan dengan kompetensi siswa yang dimilikinya. Salah satu materi yang ditawarkan di dalam program tersebut adalah materi Ilmu Pengetahuan Alam (IPA). IPA atau sains merupakan ilmu yang mempelajari gejala-gejala alam yang meliputi mahluk hidup dan mahluk tak hidup atau sains tentang kehidupan dan sains tentang dunia fisik. Pengetahuan sains diperoleh dan dikembangkan dengan berlandaskan pada serangkaian penelitian yang dilakukan oleh sainstis dalam mencari jawaban pertanyaan" apa?", "mengapa?", dan "bagaimana?" dari gejala-gejala alam serta penerapannya dalam teknologi dan kehidupan sehari-hari (Rahayu, 2012).

Identifikasi hewan termasuk dalam pembelajaran biologi yaitu ilmu sains yang mencakup materi yang sangat luas. Seringkali materi yang cukup luas menjadikan siswa bosan pada pelajaran biologi yang banyak berupa hafalan dan siswa tidak mampu memahami materi sepenuhnya. Pembelajaran konvensional dengan ceramah membuat belajar siswa menjadi pasif. Permasalahan tersebut dapat diatasi dengan menggunakan media pembelajaran yang inovatif didukung dengan kemajuan teknologi contohnya peralatan elektronik, baik teknologi digital, multimedia, hingga internet. Perkembangan teknologi ini juga diikuti dengan perkembangan ponsel yang setidaknya ada sekitar 7 miliar pengguna ponsel di seluruh dunia (Ericson, 2014). Pada ponsel memiliki aplikasi mobile berdasarkan tipe media yaitu aplikasi SMS 
(Short Message Service), mobile websites, mobile web widgets, aplikasi mobile-web, aplikasi native dan permainan (Purbasari, 2013). Namun beberapa tahun terakhir ini kepemilikan ponsel semakin meningkat terutama ponsel pintar (smartphone) yang sedang populer di dunia maupun di Indonesia.

Oleh karena itu penelitian ini bertujuan untuk menghasilkan aplikasi pembelajaran IPA yang ditujukan untuk siswa Homeschooling Pena agar dapat membantu para tutor atau pemberi materi memberikan materi pembelajaran yang menarik dan interaktif.

\section{Landasan Teori}

\subsection{Homeschooling}

Dalam bahasa Indonesia, terjemahan dari homeschooling adalah "sekolah rumah". Istilah ini dipakai secara resmi oleh Departemen Pendidikan Nasional (Depdiknas) untuk menyebutkan homeschooling. Selain sekolah rumah, homeschooling terkadang diterjemahkan dengan istilah sekolah mandiri. Homeschooling merupakan model pendidikan alternatif selain di sekolah. Pengertian umum homeschooling adalah model pendidikan di mana sebuah keluarga memilih untuk bertanggung jawab sendiri atas pendidikan anak-anaknya dan mendidik anaknya dengan menggunakan rumah sebagai basis pendidikannya. Orangtua bertanggung jawab secara aktif atas proses pendidikan anaknya. Bertanggung jawab secara aktif di sini adalah keterlibatan penuh orangtua pada proses penyelenggaraan pendidikan, mulai dalam hal penentuan arah dan tujuan pendidikan, nilai-nilai (values) yang ingin dikembangkan, kecerdasan dan keterampilan yang hendak diraih, kurikulum dan materi pembelajaran hingga metode belajar serta praktik belajar keseharian anak (Kirk, 2006).

Di Indonesia baru ada kurikulum Diknas, sedangkan di luar negeri banyak pilihan, dari yang gratis sampai yang termahal. Kurikulum dalam homeschooling tidak dipaksakan harus menginduk Diknas, namun bagi yang akan memakai kurikulum Diknas bukan suatu masalah. Biasanya yang mengacu pada kurikulum Diknas untuk 1 semester dapat ditempuh lebih cepat dengan 3 bulan.

Langkah-langkah yang dapat ditempuh dalam menerapkan kurikulum:

- Mencari dahulu kompetensi apa yang harus dikuasai anak

- Menyusun semua kompetensi yang ada

- Membuat metode yang menyenangkan dalam pembelajaran (Diyah, 2009).

Mayoritas homeschoolers memilih sendiri materi pengajaran dan kurikulumnya. Kemudian melakukan penyesuaian dengan kebutuhan anak, keluarga dan pra syarat pemerintah, diantaranya menggunakan paket kurikulum lengkap yang dibeli dari penyedia kurikulum. Dan sekitar 3\% menggunakan materi dari partner homeschooling yang dijalankan oleh lembaga setempat (Satmoko, 2010). Homeschooling pada mulanya berbentuk "Homeschooling Tunggal" yang diselenggarakan oleh satu keluarga. Kemudian mengalami perkembangan menjadi "Homeschooling Majemuk" yaitu terdiri dari beberapa keluarga dalam suatu lingkungan. Bila semakin besar maka akan terbentuk "Homeschooling Komunitas" yang membutuhkan pengelolaan yang teratur dan tersruktur (Kostelecka, 2010). Pendekatan kesetaraan dapat diterapkan untuk program homeschooling dengan harapan muatan materi ajar setara dengan program pendidikan formal dan nonformal. Berikut ini pedoman jumlah jam belajar yang setara dengan paket $\mathrm{A}, \mathrm{B}$, dan $\mathrm{C}$ yang dirancang Depdiknas.

Tabel 1. Pedoman Jam Belajar Paket A, B dan C dari Depdiknas (Depdiknas, 2006)

\begin{tabular}{|c|c|c|c|}
\hline $\begin{array}{c}\text { Paket A Setara } \\
\text { SD/MI Tahap Awal }\end{array}$ & $\begin{array}{c}\text { Paket A Setara } \\
\text { SD/MI }\end{array}$ & $\begin{array}{c}\text { Paket B Setara } \\
\text { SMP/MTs }\end{array}$ & $\begin{array}{r}\text { Paket C Setara } \\
\text { SMA/SMK/ MA }\end{array}$ \\
\hline 595 jam / tahun & 680 jam / tahun & 816jam / tahun & 969 jam / tahun \\
\hline 180 hari / tahun & 180 hari / tahun & 180 hari / tahun & 180 hari / tahun \\
\hline 3,3 jam / har & 3,8 jam / hari & 4,5 jam / hari & 5,4 jam / hari \\
\hline 34 minggu / tahun & 34 minggu / tahun & 34 minggu & 34 minggu / tahun \\
\hline
\end{tabular}




\begin{tabular}{llllll}
\hline & \multicolumn{5}{l}{ tahun } \\
\hline 30 SKS / tahun & 30 SKS / tahun & 34 SKS / tahun & 38 SKS / tahun \\
\hline Durasi @ 35 menit & $\begin{array}{l}\text { Durasi @ } \\
\text { menit }\end{array}$ & 40 & $\begin{array}{l}\text { Durasi } \\
\text { menit }\end{array}$ & @ 40 & Durasi @ 45 menit \\
\hline
\end{tabular}

\subsection{Android}

Ponsel pintar (smartphone) adalah istilah ponsel yang memiliki kemampuan multimedia dan komputing lebih menonjol daripada ponsel pada umumnya. Hal ini dikarenakan adanya operasi dan aplikasi-aplikasi penunjang yang jauh lebih menarik di dalam perangkat smartphone. Smartphone memiliki berbagai platform, misalnya platform Symbian, Blackberry, Windows, iOS, dan Android. Platform Android merupakan yang paling lengkap mulai dari sistem operasi, aplikasi, tool developing, market aplikasi dan karena adanya dukungan dari komunitas open system (Putra, 2011). Sejak pertama perkembangan platform Android, jumlah pemasaran smartphone ini cukup pesat. Menurut International Data Corporation (IDC), Android di Indonesia berhasil menguasai 52\% pangsa pasar smartphone dalam negeri (Setyadi, 2012). Hal ini disebabkan semakin terjangkaunya harga smartphone android untuk kalangan masyarakat.

\section{Perancangan Sistem}

Pada penelitian ini memiliki tahapan penelitian Prototype yang memiliki beberapa langkah penelitian seperti Gambar 1.

\section{Initial Requirement}

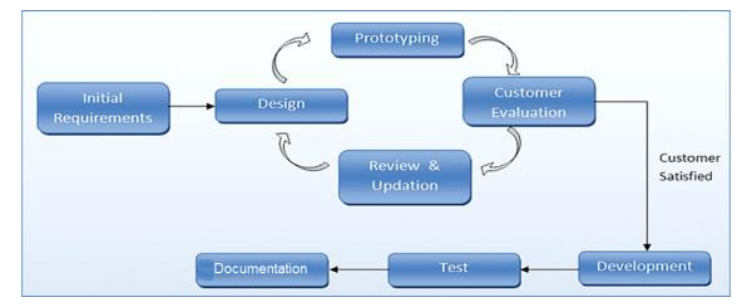

Gambar 1. Tahapan Penelitian Prototyping

Tahap Initial Requirement (penemuan kebutuhan) adalah tahap untuk menentukan tujuan dan siapa pengguna program (identification audience). Selain itu menentukan macam aplikasi (presentasi, interaktif, dan lain-lain) dan tujuan aplikasi (hiburan, pelatihan, pembelajaran, dan lain-lain). Aplikasi pembelajaran IPA pada penelitian ini ditujukan untuk siswa homeschooling setara SMP kelas 1 yang diimplementasikan menggunakan android agar pelajaran biologi lebih menyenangkan dan mudah dipahami oleh para siswa sehingga media pembelajaran yang dibuat dapat bersifat interaktif, sederhana dan materi mudah dipahami oleh siswa. Pengguna pada aplikasi ini adalah siswa (penerima materi) dan tutor (pemberi materi)

\section{Design}

Design (perancangan) adalah tahap membuat spesifikasi mengenai arsitektur program, gaya, tampilan dan kebutuhan material/bahan untuk program. Penelitian ini membuat design menggunakan storyboard yang mempunyai peranan penting dalam menerjemahkan jalannya aplikasi dalam bentuk gambar bertingkat. Gambar ini dapat memberikan petunjuk bagi pelaksana produksi. Layout, blocking, programmer, detail elemen yang digunakan untuk membangun sebuah aplikasi dan digambarkan dalam satu panel sekaligus (Mahardika, 2013). 
Tabel 2. Storyboard Aplikasi Pembelajaran IPA untuk siswa homeschooling

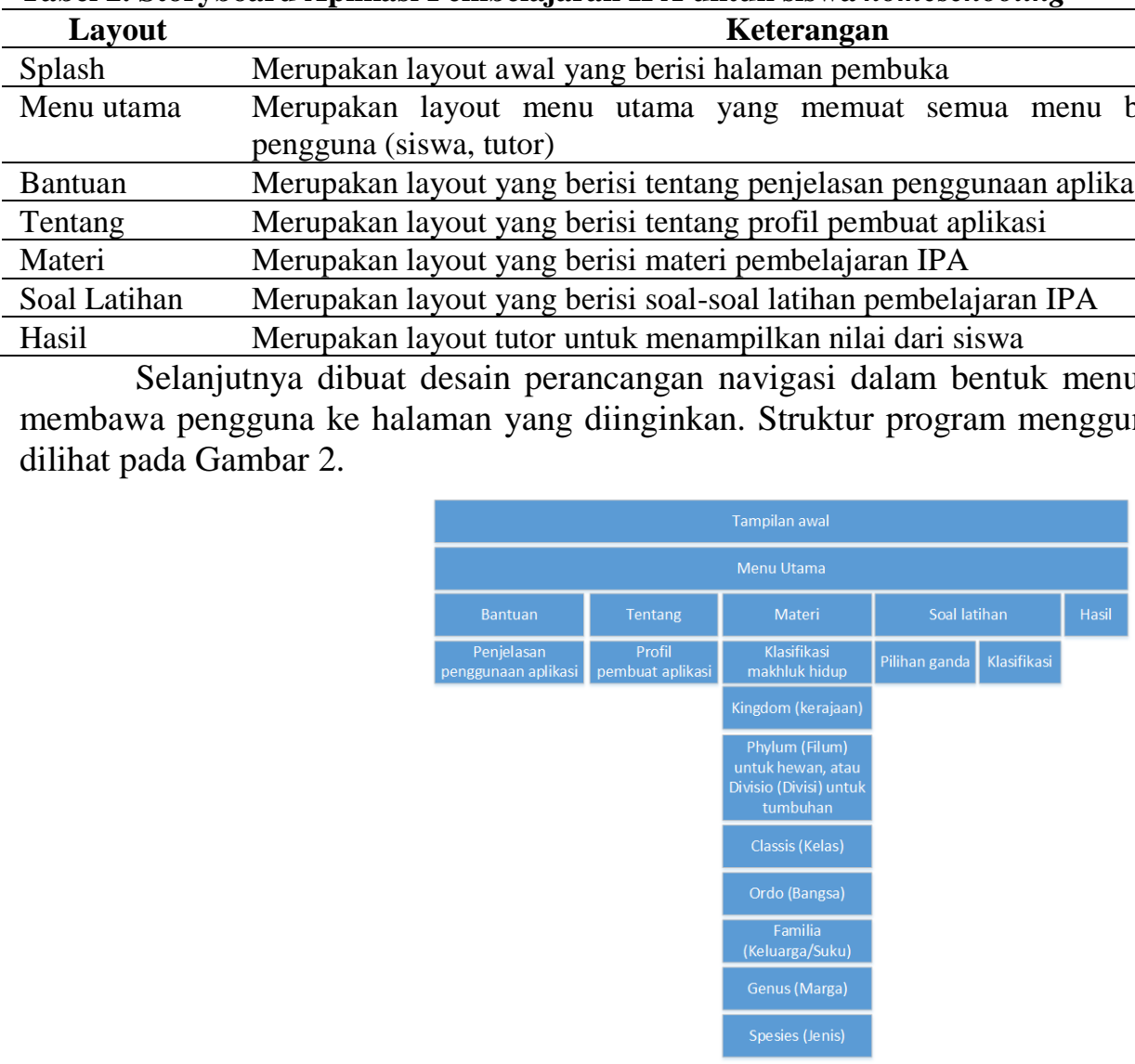

Gambar 2. Rancangan Struktur Navigasi

\section{Prototyping}

Prototyping adalah adalah tahap dimana semua objek atau bahan multimedia dibuat. Pembuatan aplikasi didasarkan pada tahap design. Tahap ini adalah tahap pembuatan seluruh objek multimedia berdasarkan perancangan yang telah dibuat sebelumnya. Penelitian ini menggunakan Adobe Flash CS6 Profesional, seperti yang terlihat di Gambar 3.

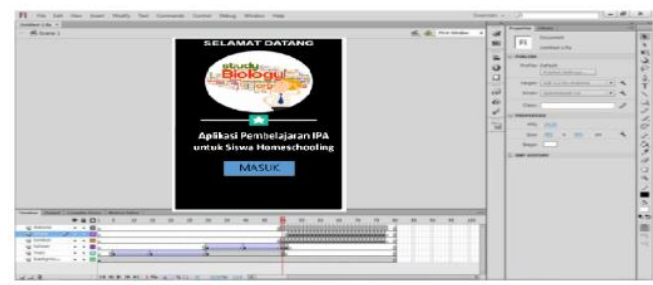

Gambar 3. Pembuatan Prototyping Aplikasi

\section{Customer Evaluation}

Customer evaluation adalah adalah tahap dimana pengguna dapat memberikan saran terhadap pembuatan aplikasi melalui prototyping yang ditampilkan. Pengguna pada tahapan ini membutuhkan lima 
tutor dari Homeschooling Pena, yang dimana satu orang dari pimpinan Homeschooling Pena dan empat tutor yang telah terbiasa memberikan materi mengenai pembelajaran IPA kepada siswanya.

\section{Review \& Updation}

Review \& Updation, pada tahapan ini peneliti mendokumentasikan saran terhadap pembuatan aplikasi. Selain itu tahap ini memastikan tidak ada lagi saran dari pengguna dengan cara melakukan kesepakatan terhadap pembuatan desain aplikasi.

\section{Development}

Development, pada tahapan ini peneliti melakukan pengembangkan aplikasi dengan cara mengumpulkan kebutuhan material untuk pembuatan aplikasi, seperti yang terlihat pada Tabel 3 .

\section{Tabel 3. Pengumpulan Material}

\begin{tabular}{|c|c|c|c|}
\hline No. & Nama & Tipe & Keterangan \\
\hline 1 & $\begin{array}{l}\text { Intro: } \\
\text { 1. Teks } \\
\text { 2. Gambar } \\
\text { 3. Masuk }\end{array}$ & $\begin{array}{l}\text { Movieclip } \\
\text { Movieclip } \\
\text { Button }\end{array}$ & $\begin{array}{l}\text { Dibuat menggunakan Adobe } \\
\text { Flash Profesional CS6 }\end{array}$ \\
\hline 2 & $\begin{array}{l}\text { Menu Utama: } \\
\text { 1. Bantuan } \\
\text { 2. Tentang } \\
\text { 3. PIlih pengguna } \\
\end{array}$ & $\begin{array}{l}\text { Button } \\
\text { Button } \\
\text { Button }\end{array}$ & $\begin{array}{l}\text { Dibuat menggunakan Adobe } \\
\text { Flash Profesional CS6 }\end{array}$ \\
\hline 3 & $\begin{array}{l}\text { Menu Bantuan: } \\
\text { 1. Teks }\end{array}$ & Teks & $\begin{array}{l}\text { Dibuat menggunakan Adobe } \\
\text { Flash Profesional CS6 }\end{array}$ \\
\hline 4 & $\begin{array}{l}\text { Menu Tentang: } \\
\text { 1. Teks }\end{array}$ & Teks & $\begin{array}{l}\text { Dibuat menggunakan Adobe } \\
\text { Flash Profesional CS6 }\end{array}$ \\
\hline 5 & $\begin{array}{l}\text { Menu Materi: } \\
\text { 1. Teks } \\
\text { 2. Klasifikasi mahluk hidup } \\
\text { 3. Gambar Mahluk hidup } \\
\text { 4. Video } \\
\text { 5. Dubbing } \\
\text { 6. Tambah materi } \\
\text { 7. Kembali }\end{array}$ & $\begin{array}{l}\text { Teks } \\
\text { Button } \\
\text { Png } \\
\text { Flv } \\
\text { Wav } \\
\text { Button } \\
\text { Button }\end{array}$ & $\begin{array}{l}\text { Dibuat menggunakan Adobe } \\
\text { Flash Profesional CS6 }\end{array}$ \\
\hline 6 & $\begin{array}{l}\text { Menu Soal Latihan: } \\
\text { 1. Jenis soal } \\
\text { 2. Pilihan ganda } \\
\text { 3. Klasifikasi } \\
\text { 4. Gambar mahluk hidup } \\
\text { 5. Video } \\
\text { 6. Dubbing } \\
\text { 7. Tambah soal } \\
\text { 8. Kembali }\end{array}$ & $\begin{array}{l}\text { Button } \\
\text { Teks } \\
\text { Png acak } \\
\text { Png } \\
\text { Flv } \\
\text { Wav } \\
\text { Button } \\
\text { Button }\end{array}$ & $\begin{array}{l}\text { Dibuat menggunakan Adobe } \\
\text { Flash Profesional CS6 }\end{array}$ \\
\hline 7 & $\begin{array}{l}\text { Menu Hasil: } \\
\text { 1. Nilai siswa } \\
\text { 2. Kembali } \\
\text { 3. Hapus Nilai } \\
\end{array}$ & $\begin{array}{l}\text { Teks } \\
\text { Button } \\
\text { Button }\end{array}$ & $\begin{array}{l}\text { Dibuat menggunakan Adobe } \\
\text { Flash Profesional CS6 }\end{array}$ \\
\hline
\end{tabular}


Pada aplikasi ini tutor dapat memilih soal latihan berdasarkan tingkatannya maupun berdasarkan spesiesnya. Selain itu tutor juga dapat memilih jenis soal latihan dengan yaitu pilihan ganda dan klasifikasi. Untuk soal latihan klasifikasi, tutor dapat mengunggah maksimal 10 gambar mahluk hidup dan menuliskan pertanyaan dari soal latihan tersebut. Siswa dapat melakukan klasifikasi berdasarkan pertanyaan yang diberikan dengan cara memilih gambar dan mengelompokannya.

\section{Testing}

Dalam penelitian ini, tahap pengujian (testing) bukan dilakukan setelah program jadi seluruhnya, tetapi dilakukan setiap konten atau setiap button. Dalam tahap ini dilakukan pengujian menggunakan black box testing. Metode black box ini merupakan pengujian program berdasarkan fungsi dari program. Tujuan dari metode black box testing ini adalah untuk menemukan kesalahan fungsi pada program. Pengujian black box berfokus pada persyaratan fungsional perangkat lunak. Pengujian ini memungkinkan analisis sistem memperoleh kondisi input yang mengerjakan seluruh keperluan fungsional aplikasi.

\section{Implementasi Sistem}

Aplikasi Pembelajaran IPA untuk Siswa Homeschooling diimplementasikan menggunakan sistem operasi Android dengan spesifikasi minimal sebagai berikut : (1) ukuran file tidak lebih dari $10 \mathrm{MB}$, (2) minimal RAM 512 MB, (3) minimal berjalan pada Android versi ICS (Ice Cream Sandwich), dan (4) layar minimal 240x320 pixel dengan landscape mode. Tampilan awal aplikasi dapat dilihat pada Gambar 4.

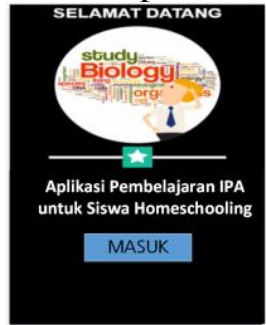

Gambar 4. Tampilan awal aplikasi

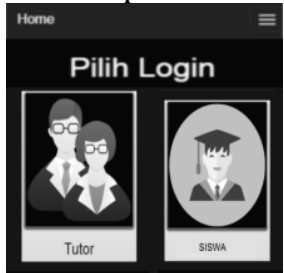

Gambar 5. Tampilan pilihan pengguna

Setelah pengguna memilih menu "Masuk", maka aplikasi menampilkan pilihan pengguna berupa Tutor sebagai pemberi materi atau siswa sebagai penerima materi, dapat dilihat pada Gambar 5. Untuk kedua pengguna tersebut, diperlukan hak akses pengguna yang membutuhkan password untuk membuka menu, dapat dilihat pada Gambar 6.

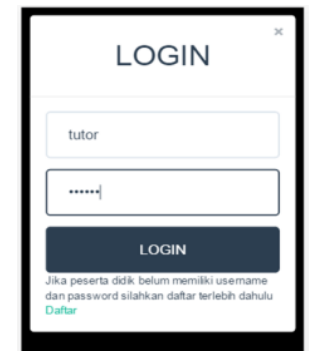

Gambar 6. Tampilan login 


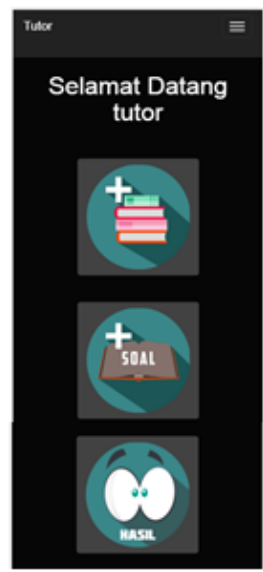

Gambar 7. Tampilan menu tutor

Pada Gambar 7 menjelaskan tentang menu tutor sebanyak tiga jenis yaitu menu untuk menambahkan materi, menu untuk menambahkan soal latihan dan menu untuk menampilkan hasil penilaian dari siswa. Selajutnya tampilan tambah materi jadi pada tampilan ini kita bisa menambahkan materi apa aja yang ingin kita tambahkan dan upload materi untuk materi yang lebih lengkapnya lagi. Untuk menambah materi, dapat dilihat pada Gambar 8.

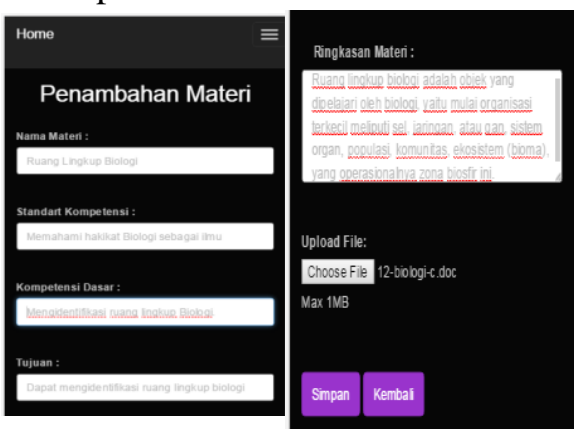

Gambar 8. Tampilan Penambahan Materi

Pada Gambar 8 menjelaskan tentang tampilan penambahan materi dengan cara memasukkan nama materinya, standart kompetensi, kompetensi dasar, tujuan dari materi tersebut dan ringkasan materi, Tutor dapat menggunakan menu upload materi saat tutor ingin mengunggah gambar, atau video ataupun slide presentasi berupa ppt.

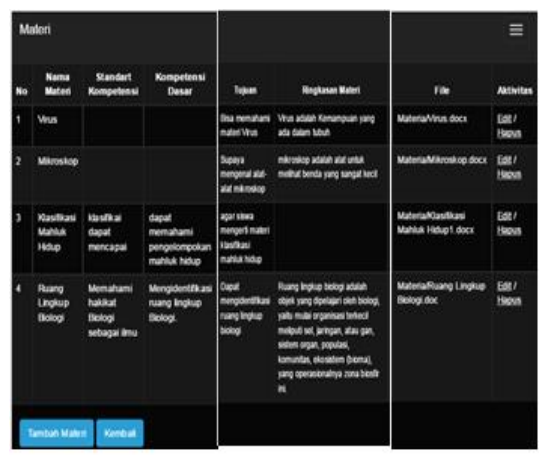

Gambar 9. Tampilan Materi 
Pada gambar 9 menjelaskan tentang tampilan materi yang telah dimasukkan tutor. Terdapat dua menu yang diberikan yaitu tambah materi untuk menambahkan materi, dan menu kembali agar tutor dapat kembali ke menu utama.

Selanjutnya kita masuk ke tampilan tambah soal di dalam tampilan tambah soal maka kita akan harus mengisikan form tambah soal, dan juga ingin pada form tambah soal ada option pilih materi yang akan kita tambahkan soalnya. Tampilan materi pada aplikasi merupakan gambar yang memanjang, sehingga peneliti melakukan print screen dengan membagi tampilan menjadi tiga tampilan.

Selanjutnya tutor dapat memilih menu Hasil untuk melihat nilai dari setiap siswa yang telah menjawab soal latihan yang diberikan. Penilaian disesuaikan dengan:

$$
\text { Score }=\frac{\text { Jumlah jawaban yang benar }}{\text { Jumlah soal latihan }} \times 100 \%
$$

Untuk tampilan Hasil, dapat dilihat pada Gambar 10.

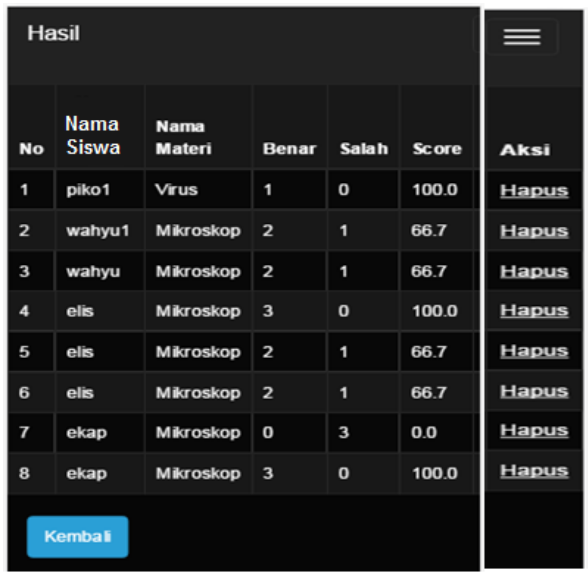

Gambar 10. Tampilan Hasil

Saat siswa ingin menggunakan aplikasi, maka tutor terlebih dahulu melakukan pendaftaran pada aplikasi. Untuk menu siswa dapat dilihat pada Gambar 11, dengan nama siswa "Rina".

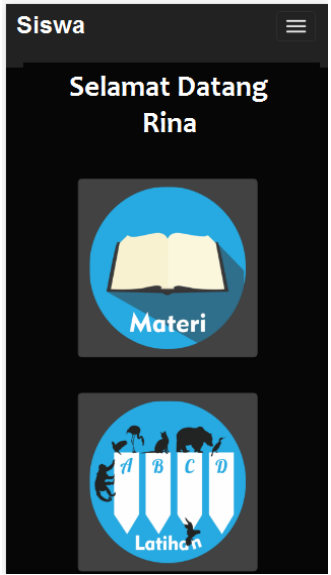

Gambar 11. Tampilan Menu Siswa 


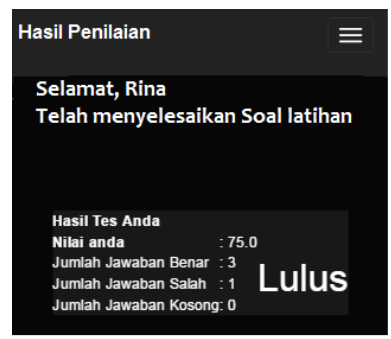

Gambar 12. Tampilan Hasil penilaian Siswa

Pada Gambar 12 menjelaskan tentang tampilan hasil penilaian, yang dimana tampilan ini disesuaikan dengan nilai siswa disesuaikan dengan jumlah jawaban yang benar dari soal latihan yang diberikan. Kategori "Lulus" diberikan saat siswa memperoleh nilai $\geq 60$.

Selanjutnya tampilan soal latihan yang berupa klasifikasi dapat dilihat pada Gambar 13, dimana siswa dapat memilih gambar mahluk hidup dan memasukkan ke kotak berwarna putih sebagai tempat untuk menyimpan jawaban. Soal latihan berupa mengelompokkan mahluk hidup yang termasuk Kingdom Animalia, dimana aplikasi dapat memberikan jawaban "Benar" saat siswa memasukkan mahluk hidup yang termasuk Animalia, dan aplikasi dapat memberikan jawaban "Salah" saat siswa memasukkan mahluk hidup yang bukan termasuk Animali.

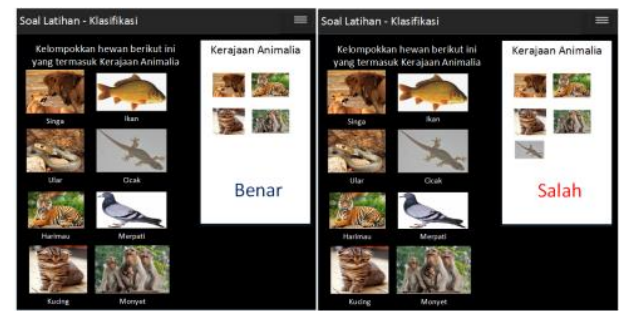

Gambar 13. Tampilan Soal Latihan - Klasifikasi

Penelitian ini juga memberikan uji coba respon pengguna berupa kuisioner kepuasan penggunaan aplikasi kepada Ahli Materi sebanyak lima orang tutor Homeschooling Pena dan dua orang praktisi sebagai Ahli Media. Selain itu penelitian ini juga memberikan kuisioner kepada siswa Homeschooling Pena sebanyak 25 orang. Analisis instrumen angket digunakan untuk menguji kelayakan produk. Instrumen ini menggunakan skala likert. Kategori jawaban yang disediakan berupa sangat setuju (SST), setuju (ST), tidak setuju (TS), sangat tidak setuju (STS). Jawaban angket diberi bobot 4,3,2,1 untuk pernyataan positif dan 1,2,3,4 untuk pernyataan negatif. Hasil skor individu dinyatakan dengan:

$$
P=\frac{f}{N} \times 100 \%
$$

Hadi (Hadi, 2015)

f adalah frekuensi yang sedang dicari persentasenya, $\mathrm{N}$ adalah Number of cases (jumlah frekuensi/banyaknya individu), dan P adalah angka persentase. Kriteria kelayakan produk terpapar pada Tabel 4.

Tabel 4. Kriteria Kelayakan Produk

\begin{tabular}{cc}
\hline Skor Angket & Kriteria \\
\hline $81,25 \% \leq$ skor $\leq 100 \%$ & Sangat Baik \\
\hline $62,50 \% \leq$ skor $\leq 81,25 \%$ & Baik \\
\hline $43,70 \% \leq$ skor $\leq 62,50 \%$ & Cukup Baik \\
\hline $25 \% \leq$ skor $\leq 43,5 \%$ & Kurang Baik \\
\hline
\end{tabular}


Hasil validasi ahli mendapatkan data kuantitatif yang diperoleh dari penilaian validator berdasarkan angket validasi dan data kualitatif didapatkan dari saran dan komentar yang diberikan oleh validator. Hasil penilaian oleh validator terhadap aplikasi kunci determinasi berbasis android dapat dilihat di Tabel 5.

\begin{tabular}{lll}
\multicolumn{3}{l}{ Tabel 5. Hasil Validator Terhadap Aplikasi Pembelajaran IPA untuk Siswa Hon } \\
\hline No & Validator & Hasil Penilaian Aplikasi \\
\hline 1 & Ahli Materi: & \\
& a. Komponen Kelayakan Isi & $72,31 \%$ \\
& b. Komponen Kelayakan Penyajian & $97,22 \%$ \\
& Rata-rata validasi ahli materi & $84,76 \%$ \\
& Kategori & Sangat Baik \\
\hline 2 & Ahli Media: & $73,45 \%$ \\
& a. Kelayakan Kegrafikan & $73,45 \%$ \\
& Rata-rata validasi Ahli Media & Baik \\
& Kategori & \\
\multicolumn{2}{l}{ Pengguna } & $92,77 \%$ \\
& a. Komponen Kelayakan Isi & $82,49 \%$ \\
& b. Komponen Kelayakan Penyajian & $86,25 \%$ \\
& c. Komponen Kelayakan Bahasa & $87,17 \%$ \\
Rata-rata validasi pengguna & Sangat Baik \\
Kategori &
\end{tabular}

\section{Penutup}

\subsection{Kesimpulan}

Dari hasil uji coba aplikasi, didapatkan kesimpulan berikut ini:

- Aplikasi Pembelajaran IPA untuk Siswa Homeschooling Pena dapat melakukan penambahan peserta didik, materi, soal latihan berupa pilihan ganda dan berupa klasifikasi

- Aplikasi Pembelajaran IPA dapat menampilkan nilai siswa sesuai dengan jumlah jawaban yang benar. Selain itu aplikasi juga dapat memberikan jawaban BENAR saat siswa berhasil mengelompokkan mahluk hidup sesuai dengan soal latihan yang diberikan, sebaliknya aplikasi dapat memberikan jawaban SALAH saat siswa melakukan kesalahan dalam mengelompokkan mahluk hidup sesuai dengan soal latihan yang diberikan.

- Aplikasi Pembelajaran IPA memiliki rata-rata validasi ahli materi sebesar 84,76 \% dengan kategori sangat baik, rata-rata validasi ahli media sebesar 73,45 \% dengan kategori Baik, dan rata-rata validasi pengguna sebesar $87,17 \%$ dengan kategori sangat baik.

\subsection{Saran}

Dari hasil uji coba aplikasi, didapatkan saran untuk pengembangan aplikasi berupa:

- Bahan materi pembelajaran IPA masih sedikit, masih memuat klasifikasi mahluk hidup. Untuk kedepannya dapat di tambahkan dengan materi yang lebih luas.

- Penambahan waktu pengerjaan soal dapat ditambahkan sebagai tolak ukur keberhasilan siswa dalam menguasai materi.

\section{REFERENSI}

Sumardiono. (2007). Homeschooling a leap for better learning. Jakarta: PT. Elexmedia Komputindo. 
Wichers, Michelle. (2006). Homeschooling: "Adventitious or detrimental for proficiency in higher education". Education Journal. Vol. 122, Iss. 1; pg. 145, 6 pg.

Saputra, Abe. (2007). Rumahku Sekolahku. Yogyakarta: GRHA PUSTAKA.

Imas Kurniasih. (2009). Homeschooling. Yogyakarta : Penerbit Cakrawala.

Winarno dan Johan Setiawan. (2013). Penerapan Sistem E-Learning Pada Komunitas Pendidikan Sekolah Rumah (Homeschooling), Ultima Infosys Vol. IV No. 1 Juni 2013, ISSN 2085-4579.

Kirk \& Winthrop, (2006). Home-Based Schooling: Access To Quality Education For Afghan Girls. Journal Of Education For International Development (2) :2.

Diyah Yuli Sugiarti. (2009). Mengenal Homeschooling Sebagai Lembaga Pendidikan Alternatif. Jurnal Edukasi, Vol. 1, No. 2, September 2009: 13 - 22

Satmoko Budi Santoso, Sekolah Alternatif, mengapa tidak? (2010). Yogyakarta : Penerbit Diva Press.

Yvona Kostelecka, (2010). Home Education In The Post-Communist Countries: Case Study Of The Czech Republic. International Electronic Journal of Elementary Education.Vol.3, Issue 1.

Direktorat Pendidikan Kesetaraan, Dirjen Pendidikan Luar Sekolah, Depdiknas. (2006). "Pendidikan Kesetaraan Mencerahkan Anak bangsa. Jakarta.

P. Rahayu, S. Mulyani, S.S. Miswadi. (2012) Pengembangan Pembelajaran Ipa Terpadu Dengan Menggunakan Model Pembelajaran Problem Base Melalui Lesson Study. Jurnal Pendidikan IPA Indonesia

Ericson. (2014). Ericson Mobility Report [online] www.ericson.com Diakses tanggal 29 September 2016.

Purbasari, R.J. (2013). Pengembangan Aplikasi Android sebagai Media Pembelajaran Matematika pada Materi Dimensi Tiga untuk Siswa SMA Kelas X. Jurnal Online Universitas Negeri Malang

Putra, Chery Dia. (2011). Aplikasi Local Directory Fasilitas Umum Berbasis Smartphone Android. Tidak diterbitkan. Skripsi. Cirebon: Universitas Islam Negeri Syarif Hidayatullah.

Setyadi, B. (2012). Android Kalahkan Dominasi BB di Indonesia [online] www. pcplus.co.id diakses tanggal 8 Januari 2016

W. S. Hadi,P. Dwijananti. (2015). Pengembangan Komik Fisika Berbasis Android Sebagai Suplemen Pokok Bahasan Radioaktivitas Untuk Sekolah Menengah Atas. Unnes Physics Education Journal

Satrya Mahardhika; A.F. Choiril Anam Fathoni. (2013). Storyboard Dalam Pembuatan Motion Graphic. Humaniora Vol.4 No.2 Oktober 2013: 1183-1189 